\title{
«PORQUE SI SE OFFRESCIERE ALGÚN AVISO O ALGUNA COSA QUE VUESTRA MERCED ME QUIERA SCREVIR DE SECRETO LE ENBÍO ESTA CIFRA». ClAVES CRIPTOGRÁFICAS CONSERVADAS EN EL ARCHIVO PARTICULAR DE JUAN RENA DURANTE EL PRIMER TERCIO DEL SIGLO XVI*
}

\author{
Fernando SERrano Larráyoz ${ }^{* *}$ \\ Universidad de Alcalá
}

\begin{abstract}
Resumen
La reciente organización realizada por el Archivo General de Navarra de los papeles procedentes del archivo particular del clérigo veneciano Juan Rena ( $c$ a. 1480-1539), mano derecha de Fernando II de Aragón (el Católico) y Carlos $\mathrm{V}$ en la reestructuración administrativa del reino de Navarra tras su conquista en 1512, ha permitido conocer diverso material criptográfico tocante a las actividades vinculadas con su persona entre 1520 y 1529 . En el presente trabajo se estudian tres cifras desconocidas hasta el momento, enmarcándolas en su contexto cronológico y relacionando sus principales características con otras claves conocidas en el ámbito hispano del siglo XVI. El desconocimiento de la existencia de este tipo de documentación relativa a las élites navarras de la Baja Edad Media y el Renacimiento las hace más interesantes, porque permite comprobar que no debieron de ser infrecuentes entre los sectores privilegiados.
\end{abstract}

\section{Palabras clave}

Juan Rena, Juan Vallés, Juan de Alarcón, reino de Navarra, sistemas de cifrado, claves, criptografía, siglo XVI.

\footnotetext{
Abstract

Diverse cryptographic material has come to light during the recent rearrangement, carried out by the General Archive of Navarre, of several documents coming from the personal archive of Venetian clergyman Juan Rena (ca.1480-1359). Rena was the right-hand man of Ferdinand II of Aragon, called the Catholic, and Charles V, during the administrative restructuring of the Kingdom of Navarre after its conquest in 1512. The material found relates to his activity during the period from 1520 to 1529 . The present study focuses on three ciphers unknown so far, placing them in their chronological context and

Este estudio ha sido realizado en el marco del proyecto de investigación FFI2011-29117-C02-01 (20122015) concedido por el Ministerio de Ciencia e Innovación (ahora Ministerio de Economía y Competitividad). Quiero agradecer los comentarios y sugerencias realizadas por Juan Jesús Virto Ibáñez, Fermín Miranda García, Peio Monteano Sorbet, Félix Segura Urra, Pablo Sastre Fraile y Álvaro Adot Lerga.

** Universidad de Alcalá. E-mail: fernando.serranol@uah.es.
} 
analysing their main features in relation to other known keys from the Hispanic $16^{\text {th }}$ century sphere. These findings are of particular interest due to the lack of information about the existence of this kind of documents, linked to Navarrese elites in the Late Middle Ages and the Renaissance, because they allow us to check that they must not have been uncommon among privileged sectors.

\section{Keywords}

Juan Rena, Juan Vallés, Juan of Alarcón, Kingdom of Navarre, ciphers, keys, cryptography, $16^{\text {th }}$ century.

\section{Résumé}

La réorganisation récente menée par l'Archive Général de Navarre des archives privées du clerc vénitien Juan Rena (ca. 1480-1539), bras droit de Ferdinand II d'Aragon (le Catholique) et de Charles $\mathrm{V}$ pendant la restructuration administrative du Royaume de Navarre après sa conquête en 1512, a permis de découvrir un riche matériau cryptographique concernant les activités liées à sa personne pendant la période 1520-1529. Dans le présent article, on étudie trois chiffres inconnus jusqu'à présent, en les replaçant dans leur contexte chronologique et en rapprochant leurs caractéristiques principales d'autres clés liées au monde hispanique du XVI ${ }^{\mathrm{e}}$ siècle. La méconnaissance de l'existence de ce type de documents relatif aux élites navarraises du Bas Moyen Age et de la Renaissance les rend plus intéressantes, car ils démontrent qu'ils ne devaient pas être rares à l'époque dans les milieux privilégiés.

\section{Mots-Clés}

Juan Rena, Juan Vallés, Juan de Alarcón, Royaume de Navarre, chiffres, clés, cryptographie, XVI ${ }^{\mathrm{e}}$ siècle.

El interés por mantener en secreto diferentes asuntos que por su materia podrían llegar a incomodar a los implicados suscitó, ya desde épocas antiguas, la utilización de escrituras cifradas, cuya lectura necesitaba conocer una serie de claves. Lejos queda la afirmación de Rafael Conde y Delgado de Molina, con relación a los estudios sobre la criptografía hispánica, cuando escribió hace más de treinta años, que no eran precisamente abundantes las noticias al respecto ${ }^{1}$. De un tiempo a esta parte la investigación sobre criptografía, es decir, la ciencia que estudia la escritura oculta, ha dado sus frutos con el descubrimiento de nuevos textos codificados y descifrado de claves. Todo ello con sus publicaciones correspondientes ${ }^{2}$.

\footnotetext{
Rafael Conde y Delgado de Molina, "Una clave criptográfica relacionada con la Germanía Valenciana”, Saitabi, 28 (1978), p. 25.

2 Como monografías generales más actualizadas pueden citarse el ya clásico trabajo de Juan Carlos Galende Díaz, Criptografía. Historia de la escritura cifrada, Universidad Complutense, Madrid, 1995; o más recientemente el de Jesús Javier Ortega Triguero, Miguel Ángel López Guerrero y Eugenio C. García del Castillo Crespo, Introducción a la criptografía: Historia y actualidad, Universidad de Castilla-La Mancha, [Murcia], 2006. Desde un punto de vista divulgativo pero muy acertado en su exposición, véase Simon Singh, Los códigos secretos. El arte y la ciencia de la criptografía, desde el antiguo Egipto a la era de Internet, Debate, Madrid, 2000. Para época altomedieval aludir al trabajo del mencionado Juan Carlos GALEnde DíAz, "Elementos y sistemas criptográficos en la escritura visigótica”, VIII Jornadas cientificas sobre documentación de la Hispania altomedieval (siglos VI-X), Universidad Complutense, Madrid, 2009, pp. 173-183. Por lo que respecta al reino de Castilla, donde apenas hay vestigios de escritura cifrada hasta los Reyes Católicos, sin ánimo de ser exhaustivos, se puede citar otro estudio del mismo autor, Juan Carlos Galende DíAz, "La criptografía medieval: El libro del Tesoro", II Jornadas cientificas sobre documentación de la corona de Castilla (siglos XIII-XV), Cema, Madrid,
} 
Desde el siglo XVI se desarrolla la criptografía, por causas tan diversas como «el establecimiento con carácter permanente de embajadas y secretarías de Estado, el incremento de las relaciones internacionales y, en consecuencia, la necesidad de asegurar el secreto de la correspondencia» ${ }^{3}$. El reinado de Carlos V es el momento clave del desarrollo criptográfico. Si a nivel europeo se asiste a una consolidación de su uso, en el territorio hispano aumenta tras un periodo de transición, primero en el reinado de los Reyes Católicos y su perfeccionamiento posterior en el de Felipe II. A todo esto hay que añadir el nacimiento de la criptografía en las Indias Occidentales, tras el descubrimiento y posterior conquista, que tendrá sus propias peculiaridades ${ }^{4}$.

Durante el Renacimiento puede establecerse el tránsito entre la sencillez y la dificultad en la evolución de la criptografía hispana. De la sencilla criptografía propia del periodo medieval, de la que existen buenos ejemplos en la Corona de Aragón ${ }^{5}$, al contrario

2003, pp. 41-77. Para la España del siglo XVI pueden destacarse los trabajos pioneros de Mariano ALCOCER, "Criptografía española”, Revista Histórica, 1 (1918), pp. 46-50; "Criptografía española", Revista de Archivos, Bibliotecas y Museos, 42 (1921), pp. 628-640; "Criptografía española", Boletín de la Real Academia de la Historia, 105 (1934), pp. 336-340; Criptografía española, Tipografía de Archivos Madrid, 1934; "Criptografía española", Boletín de la Real Academia de la Historia, 106 (1935), pp. 603-676; Pierre Spezali, "Aspects de la cryptographie au XVI $\mathrm{X}^{\mathrm{e}}$ siècle", Bibliothèque d'Humanisme et Renaissance. Travaux et documents, 17/2 (1955), pp. 188-206; y más recientemente Juan Carlos GaLENDE DíAz, "La correspondencia cifrada del embajador Lope de Soria", Hispania. Revista de Historia, 52/181 (1992), pp. 493-520; "La escritura cifrada durante el reinado de los Reyes Católicos y Carlos V", Cuadernos de estudios medievales y ciencias y técnicas historiográficas, 18-19 (1993-1994), pp. 159-178; "Criptografía moderna: curioso cifrado entre el obispo Diego de Muros y los Reyes Católicos", Boletín del Real Instituto de Estudios Asturianos, 144 (1994), pp. 385-398; "Diplomacia cifrada hispánica durante el siglo XVI", Revista Digital Universitaria [en línea], 7/7 (2006). Disponible en: http://www.revista. unam.mx/vol.7/num7/art53/jul_art53.pdf [consultado el 6 de febrero de 2014], y Juan Carlos GALENDE Díaz y Manuel Salamanca López, "El arte de escribir cifrarios en tiempos del emperador Carlos V", El Emperador Carlos y su tiempo: Actas IX Jornadas Nacionales de Historia Militar, Sevilla 24-28 de mayo de 1999, Deimos, Madrid, 2000, pp. 963-978. Muy completo también el panorama histórico que se ofrece sobre la evolución de la criptografía, en Pedro Luis Lorenzo Cadarso, "Los documentos cifrados en la Corte de Fernando VI (1746-1759)", Espacio, Tiempo y Forma, Serie IV, Historia Moderna, 11 (1998), pp. 360-364. En lo referente al conjunto de directrices y normas prácticas para el criptoanálisis de textos cifrados, Juan Carlos Galende Díaz, "Principios básicos de la criptología: el manuscrito 18657 de la Biblioteca Nacional", Documenta \& Instrumenta, 4 (2006), pp. 47-59, y Sara Gómez Hernández, Análisis de textos cifrados de los siglos XVI y XVII [en línea], Universidad Carlos III, Madrid, 2010. Disponible en: http://e-archivo.uc3m.es/handle/10016/11110 [consultado el 27 de diciembre de 2013].

3 Juan Carlos Galende Díaz, "La criptografía medieval...", p. 43.

4 Juan Carlos Galende Díaz, "Sistemas criptográficos empleados en Hispanoamérica", Revista Complutense de Historia de América, 26 (2000), pp. 57-71.

5 Algunos ejemplos, en Xavier de Salas Bosch, "Una lletra cifrada en catalá", Estudis. Universitaris Catalans, 16 (1931), pp. 373-377; Josep Ma Pons I GuRI, "Característiques paleográfiques dels 1libres notarials catalans fins el 1351", VII Congreso de Historia de la Corona de Aragón (1-6 octubre 1962). Crónica, ponencias y comunicaciones, Direcciones Generales de Archivos y Bibliotecas y de Relaciones Culturales, Barcelona, vol. 3, 1962, pp. 225-248; Antoni Ma Aragó, "Una clau criptogràfica del segle XV", Cuadernos de arqueología e historia de la ciudad de Barcelona, 12 (1968), pp. 171-176; Josepa Cortés Escrivá y Vicent Pons Alós, "Una clau criptográfica d’Alfons el Magnánim per a la guerra amb Castella (1429)", Saitabi, 36 (1986), pp. 25-36. Otras referencias se pueden consultar en Juan Carlos GaLende Díaz, "La escritura cifrada...", p. 160. 
que en el reino de Castilla, y cuya práctica no es desconocida en Navarra ${ }^{6}$, en la Edad Moderna se complica la configuración de criptogramas. Entre estas complicaciones, parece que resulta habitual la aparición de los elementos nulos e inertes y de otros que servían para duplicar una letra, dificultades todas ellas «con el fin de obstaculizar la lectura del documento cifrado, ya que cada vez era más habitual la existencia de hábiles funcionarios capacitados en su decodificación ${ }^{7}$. El desarrollo de la práctica criptográfica hay que buscarla en la Italia del siglo XV, tanto en las cortes principescas como en la curia pontificia. En esta última destaca León Battista Alberti (1404-1472), secretario pontificio y autor de un conocido Trattati in cifra (publicado en Roma en 1470) . $^{8}$

Por lo que respecta al método más habitual utilizado en la correspondencia diplomática moderna cuando se quería guardar algo en secreto, nos encontramos con el denominado 'nomenclátor', integrado por un alfabeto, la mayoría de las veces homofónico', y un código de símbolos especiales que se correspondían con términos de utilización frecuente. De igual forma estos términos también podían construirse de dos maneras: mediante palabras de sentido oculto, aunque de comprensión directa, y mediante grupos de letras, generalmente bigramas y trigramas de significado convencional. $\mathrm{La}$ elaboración de los textos se basaba en un sistema de sustitución simple. Los principales inconvenientes que tenía este método era que el receptor del mensaje debía conocer la clave completa para poderlo interpretar y que solo se podían transmitir los testimonios que tuvieran su correspondencia cifrada, además de ser complicado cambiar el implemento en caso de variar el código y que su desciframiento podía basarse en el examen de las frecuencias ${ }^{10}$. Un tipo de documento, el criptográfico, cuyo uso pasó de ser casi exclusivo de las cancillerías regias durante la Baja Edad

\footnotetext{
6 En los últimos años han sido estudiadas tres claves que corresponden a los reinados de Carlos II de Navarra, fechada hacia 1376 o 1377 (María NARBONA CÁRCELEs, "Ordo su regula occulte scribendi. Un cifrado para interpretar mensajes en clave en el contexto de la Guerra de los Cien Años", Aproximación a la historia social del lenguaje. España, siglos XIV-XVIII, Jesús Usunáriz Garayoa y Rocío García Bourrellier (eds.), Iberoamericana, Madrid, 2005, pp. 85-127), de Carlos III de Navarra, fechada entre 1394 y 1406 (Fernando Serrano Larráyoz, "Una clave criptográfica de la cancillería de Carlos III 'el Noble' de Navarra", Príncipe de Viana, 215 (1998), pp. 171-181) y de Juan III y Catalina I, fechada en 1507 (Álvaro Adot Lerga, Embajadores navarros en Europa. Orígenes de la diplomacia moderna navarra, Pamiela, Pamplona, 2012, pp. 37-56).

7 Juan Carlos Galende Díaz y Manuel Salamanca López, "El arte de escribir cifrarios...", p. 968. No obstante, alguna de estas prácticas, como la inclusión de signos sin significado queda bien reflejado en la clave de la cancillería navarra, fechada entre finales del siglo XIV y principios del XV: «nichil significantes» (Fernando Serrano Larráyoz, "Una clave criptográfica...", p. 175); y en la de Alfonso el Magnánimo, de 1429: «nichil importantes» (Josepa CorTés Escrivá y Vicent Pons Alós, "Una clau criptográfica...”, p. 28).

8 Sobre la evolución de la criptografía en Europa durante el siglo XVI, véase Juan Carlos GaLendE Díaz y Manuel Salamanca López, "El arte de escribir cifrarios...", pp. 964-967.

9 El término hace referencia a aquellos símbolos que siendo diferentes representan una misma grafía (Juan Carlos Galende Díaz, "Principios básicos de la criptología...", p. 53).

10 Juan Carlos Galende Díaz, "Diplomacia cifrada hispánica...", p. 5. Respecto al fenómeno de las frecuencias relativas de las letras en los distintos idiomas, Cicco Simonetta, secretario del duque de Milán, codificó hacia 1474 distintas reglas para descifrar escritos secretos sin conocer la clave. En esta línea trabajaron también Matteo Argenti, uno de los cifradores de la curia pontificia, y Dominique de Gabre, obispo de Lodève y embajador de Enrique II de Francia en Venecia hacia 1550 (Rafael Conde y Delgado DE Molina, “Una clave criptográfica...," p. 27).
} 
Media a formar parte de una práctica más o menos habitual entre aquellos miembros pertenecientes a las élites vinculadas con los distintos monarcas y que tenían mucho que esconder con el fin de lograr sus propósitos.

En este trabajo presentamos tres claves conservadas entre en la correspondencia personal que Juan Rena mantuvo con sus más fieles servidores de aquella época. Veneciano de origen este eclesiástico nació hacia el año 1480, sin que conozcamos dato alguno sobre su familia o sobre dónde adquirió la sólida formación que le llevó a desempeñar puestos de responsabilidad en la administración castellana desde principios del siglo XVI. Lo cierto es que su periplo político-administrativo y su estatus religioso, le permitieron ocupar el obispado de Pamplona al final de su vida. Nombrado capellán de la reina Juana I de Castilla en 1508, fue mano derecha de Fernando II de Aragón (el Católico) tras la conquista de Navarra en su reestructuración administrativa, ejerció entre otras actividades como pagador de las obras y gastos extraordinarios de Navarra entre 1512 hasta su muerte y participó activamente en la toma del castillo de Maya en el verano de 1522. Como capellán de Carlos I sirvió en numerosos cometidos a la corona española. Las prebendas eclesiásticas de las que fue beneficiario y que tanto ansiaba fueron constantes a partir de 1523 , ejerciendo como tesorero de la catedral de Pamplona entre 1530 y 1538. La anhelada mitra episcopal de la diócesis de Pamplona le llegó en la primavera de ese año de $1538^{11}$.

La más antigua de las claves que se presentan es una sencilla cifra enviada por Juan Vallés a finales de 1520. Más dificultades tiene para poder establecer una cronología y atribuirla a unos hechos lo más precisos posibles la referida al periodo entre 1521 y 1524. Así, los términos escogidos para confeccionar el vocabulario cifrado hacen referencia a cuestiones diplomáticas y bélicas que hacen intuir que los asuntos que se trataron con esa clave guardan relación con la estrategia de defensa del reino y la política internacional en ese periodo. Por último se va a aludir a una clave perteneciente a Juan de Alarcón, utilizada probablemente en 1529.

\section{La cifra para la correspondencia con Juan Vallés (1520)}

Desde no hace mucho tiempo la figura de Juan Vallés ha sido estudiada en profundidad. Nombrado protonotario de Navarra en 1524 y tesorero cuatro años después, alcanzó grandes cotas de poder, en buena medida gracias a la intermediación de Juan Rena y su buen hacer posterior. A finales del año 1518 o principios del siguiente, Vallés deja su

\footnotetext{
11 Sobre la biografía de Juan Rena deben consultarse necesariamente José GoÑ GazTAmBide, Historia de los obispos de Pamplona, siglo XVI, Ediciones Universidad de Navarra-Gobierno de Navarra, Pamplona, vol. 3, 1985, pp. 254-282; Peio J. Monteano Sorbet, "El pagador real micer Juan Rena (c. 1480-1539). Hombre clave en la conquista de Navarra", Tesoreros, «arrendadores» y financieros en los reinos hispánicos: la Corona de Castilla y el reino de Navarra (siglos XVI-XVII), Ernesto García Fernández e Inmanol Vítores Casado (eds.), Instituto de Estudios Fiscales, Madrid, 2012, pp. 123-135; y Mercedes Chocarro Huesa y Félix Segura Urra, Inventario de la documentación de Rena. Archivo Real y General de Navarra, Gobierno de Navarra, Pamplona, 2013, pp. 37-68.
} 
casa y el oficio de notario en el pueblo navarro de Villafranca y marcha al servicio del rey Carlos I. Durante sus servicios al monarca Habsburgo, principalmente en actividades cancillerescas y diplomáticas por gran parte de Europa ${ }^{12}$, tuvo a bien no sólo proteger sus ambiciones personales en el siempre intrigante ámbito cortesano sino también los de su valedor, Juan Rena. Esto queda reflejado en una misiva escrita desde Colonia, el 12 de noviembre de 1520 , donde expone que:

«(...) vuestra merced de aquí adelante me terna por uno de sus verdaderos criados y servidores, que en verdad para mí es harto porque soy cierto que vuestra merced me podrá hazer más mercedes que yo a él servicios, y porque esta merced sea para mí complida (...) me encomiende sus cosas y negocios para que más abiertamente vuestra merced conozca por las obras mi desseo de servir y specialmente para en todo lo que se offrezca en Roma, pues tengo mano para ello, le supplico no se sirva de otros servidores que de mí $(\ldots)^{13} \ggg$.

Los intereses de Juan Rena por acumular cargos y beneficios eclesiásticos son bien conocidos y la presencia del joven Vallés en la corte era una baza que no había que desestimar. La enrarecida situación política del reino sirvió de acicate al veneciano a la hora de obtener prebendas y cargos eclesiásticos que le permitieran controlar a los partidarios de los destronados reyes de Navarra. El monasterio de Urdax, en pleno Pirineo, cobijo de disidentes bajo la protección del abad Juan de Orbara, estuvo en su punto de mira. Sin duda los intereses en Roma a los que alude Vallés en su carta, tuvieran que ver con las misivas enviadas al embajador español en la corte papal con el fin de obtener de León X este abadiado de Urdax para su mecenas, intento que al final no consiguió ${ }^{14}$.

Más explícita es la misiva, fechada en Worms, el 5 de diciembre de 1520, donde Juan Vallés indica la cifra que podían utilizar en en posteriores comunicaciones. En ella refiere a Juan Rena que «las cartas para Roma sobre la abbadía de Urdaix las quales he despachado (...) las havemos remittido a Roma a buen recaudo». En esta carta se vuelve a comprobar abiertamente el reconocimiento de Vallés a su valedor:

«Ya screví a vuestra merced que para que yo conozca que vuestra merced me tiene por verdadero servidor, me mande enteramente todo lo que por acá se le

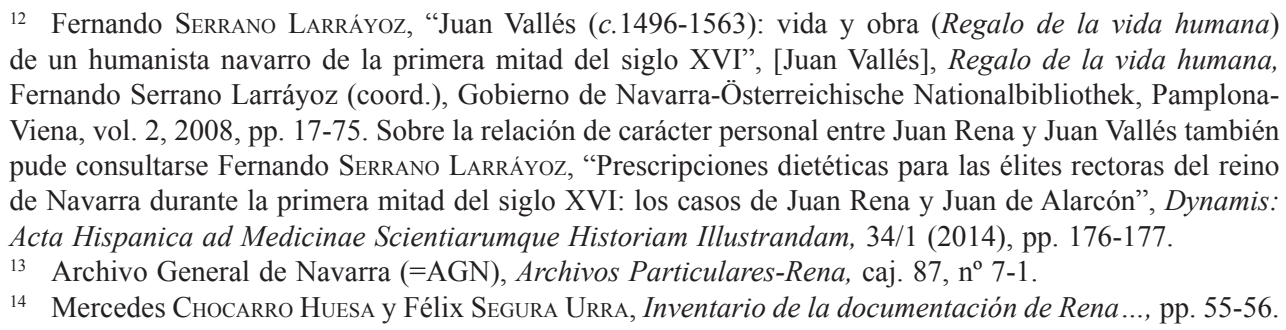


offrezca, para que por más obras conozcan mi desseo de servirle en esto de Urdaix yo terné tal cuidado que spero en Dios saldré con mi intención (...)».

Además del tema prioritario, el envío de cartas a Roma, Juan Vallés aprovecha su condición de servidor privilegiado para solicitar, en la medida de lo posible, que Rena le consiga acceder a algunas de las secretarías del reino de Navarra «en caso que vacasse (...) porque ya ve vuestra merced que el officio que más me satishaze según mi Arte es éste» ${ }^{15}$. Antes ya, en la citada carta de noviembre, le solicita la «promesa del duque [de Nájera $]^{16}$ que vacando un offico de oydor de comptos o maestre finanças o secretario 0 alguna de las merinías me proveherá d'ella» ${ }^{17}$. Continua la carta de diciembre suplicando se le pague a su padre la cantidad de doscientos robos de cebada que «los de la capitanía de Valençuela y sin licencia ni sabiduría suya» habían tomado, y un cargo u oficio para un hermano suyo «que estaba en Aragón (...) sin ningún partido». Finaliza con una cifra por «si se offresciere algún aviso o alguna cosa que vuestra merced me quiera screvir de secreto». Un hecho nada sorprendente si se tiene en cuenta, como se ha podido comprobar, las actividades de Juan Vallés en la corte y la necesidad de mantener en secreto sus intereses y los de su protector. Dicha cifra es muy sencilla y no tiene ninguna particularidad especial, correspondiéndose con un alfabeto en que cada letra tiene solamente un carácter criptográfico que se relaciona con signos (ideogramas) o números:

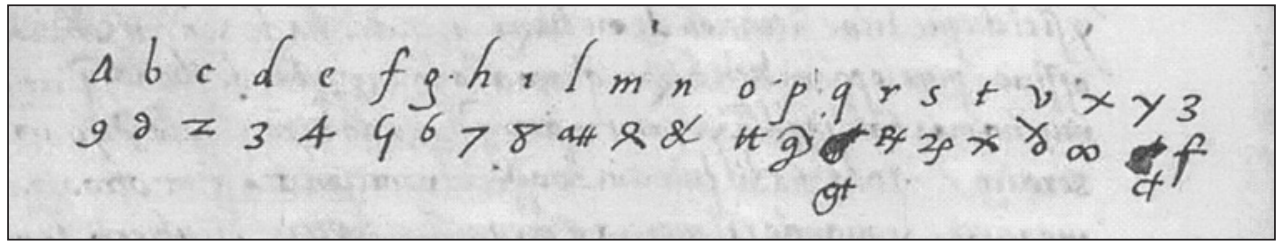

\section{La cifra para la correspondencia relacionada con la defensa del reino [1521-1524]}

De esta segunda clave, no sabemos con seguridad quién o quiénes la pudieron utilizar. El hecho de que los términos de la clave estén redactados en lengua italiana ha de tenerse en cuenta. Quizás su uso pueda vincularse con la correspondencia mantenida entre Juan Rena y alguno de sus espías italianos. El periodo cronológico de utilización de la clave también es complicado de fijar. Con todo, y a tenor de posteriores investigaciones, nos inclinamos por la hipótesis de que pudo ser usada en relación con los acontecimientos políticos y bélicos que involucraron a Navarra entre 1521 y 1524 .

5 AGN, Archivos Particulares-Rena, caj. 87, no 7-2.

16 En esas fechas, el II duque de Nájera, Antonio Manrique de Lara y Castro, era el virrey de Navarra.

17 AGN, Archivos Particulares-Rena, caj. 87, $\mathrm{n}^{\circ}$ 7-1. 
La reflexión hay que fijarla en los signos que representan los conceptos que se desarrollan en la clave. De todos ellos llama la atención que Fuenterrabía se encuentre entre ellos. Aunque ya desde el periodo medieval siempre había sido una plaza de importancia, ¿cuándo Fuenterrabía tuvo la suficiente entidad como para 'merecer' un término específico en la correspondencia internacional junto con Bayona y Pamplona? Evidentemente tiene que corresponder a un momento en que dicha plaza adquiera un protagonismo inapelable en las relaciones europeas. Y eso sobre todo se da entre la segunda mitad de 1521, es decir, el periodo en que las negociaciones internacionales (entiéndase conferencias de Calais) derivaron, entre otros asuntos, sobre la restitución de Navarra al rey de Francia Francisco I, recientemente recuperada por Carlos V. Lo cierto es que en el enfrentamiento franco-imperial, en el que ambos bandos pretenden atraerse a Inglaterra, Fuenterrabía era fundamental. España trataba de aproximarse a Enrique VIII ofreciéndole la recuperación de la Guyena (ya lo había hecho Fernando II de Aragón). Para participar en la campaña, el ejército inglés debía desembarcar en Fuenterrabía o al menos penetrar en Francia a través de ella, como había ocurrido en 1512. Por otro lado, Fuenterrabía abría la puerta a Castilla en caso de una invasión francesa. De parecido modo, la referencia a los mercenarios suizos «sgniçari» ${ }^{18}$ no está fuera de contexto puesto en esos años -1521-1524- Carlos V intentó interponerse en las negociaciones de Francisco I con los mercenarios suizos con el fin de evitar que tomasen partido por el francés, al igual que el término «armata» (armada), que puede aludir indistintamente a soldados de tierra o fuerzas navales. La importancia de la plaza de Fuenterrabía fue tal que dio nombre al tratado de del mismo nombre, acordado a mediados de febrero de 1524, entre Carlos V y Francisco I. Este último dejaba en manos del Emperador la fortaleza, en manos francesas desde octubre de $1521^{19}$.

Otro asunto a tener en cuenta es el hecho de que la clave no aluda al rey o a los reyes de Navarra (Juan III murió en junio de 1516 y Catalina I en febrero de 1517) pero sí al «regno de Navarra». Esto parece que corresponde a un momento en que el rey o los reyes apenas tienen protagonismo político, algo que no concuerda con el reinado de Juan y Catalina, que mantuvieron por unos años una actividad diplomática propia. Circunstancia que no ocurrió, al parecer, con Enrique II, siempre a la sombra de su mentor y luego cuñado Francisco I. Una reflexión que quedaría zanjada salvo por el hecho de que se articule un signo diferente para el Emperador y para el rey de España, que en el periodo de datación propuesto coincidían en la persona de Carlos

\footnotetext{
18 Se entiende que hace referencia a 'esguízaro', es decir, suizo, palabra que existe en castellano y que en italiano antiguo era 'sguizaro', en plural 'sguizari' (suizos).

19 Sobre estas cuestiones, en especial las referentes a la importancia de Fuenterrabía, véase Peio J. Monteano Sorbet, La Guerra de Navarra (1512-1529). Crónica de la conquista española, Pamiela, Pamplona, 2010, pp. 268-270 y 316-322, y De Noáin a Amaiur (1521-1522). El año que decidió el futuro de Navarra, Pamiela, Pamplona, 2012, pp. 103-136.
} 
$\mathrm{V}$, uso poco probable porque, salvo error, en la correspondencia diplomática europea y también en la española se le denomina casi siempre Emperador ${ }^{20}$.

Por lo que respecta al análisis propiamente criptográfico de la cifra, ésta ese compone de un alfabeto en que a cada letra del abecedario le corresponde de manera aleatoria otra letra, con las excepciones de la «a», «b» $\mathrm{y}$ «r» a las que son asignados signos y de la «u» $\mathrm{y}$ « $\mathrm{x} »$ que las representan números. Además se comprueba que el redactor del alfabeto anotó la «Z» antes de la «y»:

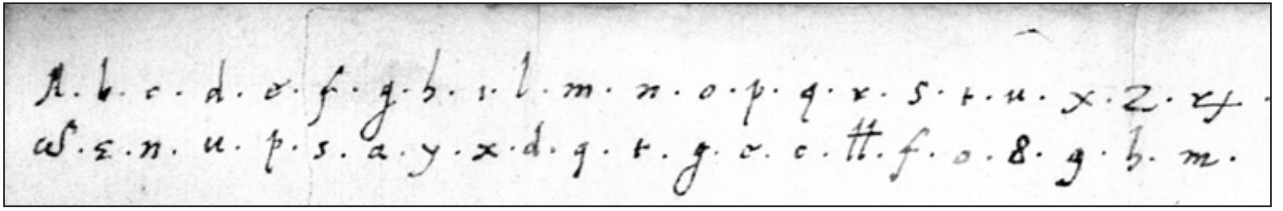

A continuación quedan manifestados dieciocho bloques de cinco sílabas, compuestos por las consonantes del alfabeto y las cinco vocales (bigramas), con la excepción de «y», más dos vocales «ì $\mathrm{y}$ «u», que en ese periodo poseían valor consonántico «j»y «V» respectivamente. A cada una de las sílabas le corresponde un signo (ideograma):

20 Otro planteamiento, si se tienen en cuenta las referencias por separado al Emperador y al rey de España (denominación esta que en Italia utilizan ya para Fernando II de Aragón) invita a pensar que la clave es anterior a 1520, antes de la muerte del Emperador Maximiliano I de Habsburgo (12 de enero de 1519). Esto nos lleva a considerar que dicha clave pudo estar relacionada con el periodo de tensión que se vivió en Navarra tras la finalización de la tregua franco-española a principios de 1515. De hecho, en enero de ese año la corte de Fernando II de Aragón ( $† 23$ de enero de 1516) advertía que Francisco I preparaba un ejército, aunque se desconocía si era para atacar Navarra o para socorrer a Milán, y ante la duda el rey de España organizó la defensa del reino navarro (Peio J. Monteano Sorbet, La Guerra de Navarra ..., pp. 133-135). La clave también pudo estar relacionada no solo con la aludida estrategia defensiva del reino sino con cuestiones tocantes a la batalla de Marignano, acaecida a mediados de septiembre de 1515, entre los ejércitos aliados del rey de Francia y la república veneciana contra las fuerzas de la Confederación de Suiza, dueñas del ducado de Milán. Así, como en la hipótesis principal, todos los personajes aludidos en dicha clave participaron, de un modo u otro, en el desarrollo de los acontecimientos, véase Cesare AMELI, La battaglia di Marignano detta dei Giganti, Edizioni Istituto Storico Melegnanese, [s.1.], 1965. Sobre la actividad diplomática de Fernando el Católico durante 1515 y su relación con Navarra y la toma del ducado de Milán por parte del rey de Francia, véase Ma Isabel Ostolaza Elizondo, Juan Ignacio Panizo Santos y Ma Jesús Berzal Tejero, Fernando el Católico y la empresa de Navarra (1512-1516), Pamplona, Gobierno de Navarra, 2011, regestas documentales $n^{\circ}$ 828, 837, 888, 891, 896-899, 905, 910-911, 916917 y 924 . Sin embargo en ningún momento la clave alude a Milán, que sería lo más plausible, sino que se recoge el término «Ducados» (en plural), a mi entender haciendo referencia a cuestiones monetarias (ducados de oro), probablemente distintos gastos en el mantenimiento de gentes de armas y de las plazas fuertes de Fuenterrabía o Pamplona. Hipótesis de trabajo en espera de futuras investigaciones. Quiero agradecer las opiniones aportadas sobre estas cuestiones a Álvaro Adot Lerga, Peio Monteano Sorbet y Félix Segura Urra. Fermín Miranda Garcia, por su parte, a quien también agradezco sus comentarios, no tiene tan claro que el término «Ducados» se refiera a monedas, porque es la única referencia al margen de cuestiones de carácter político. Propone que tal vez haga mención de forma conjunta a los ducados de Saboya y Milán, objeto fundamental del interés de Francisco I. 


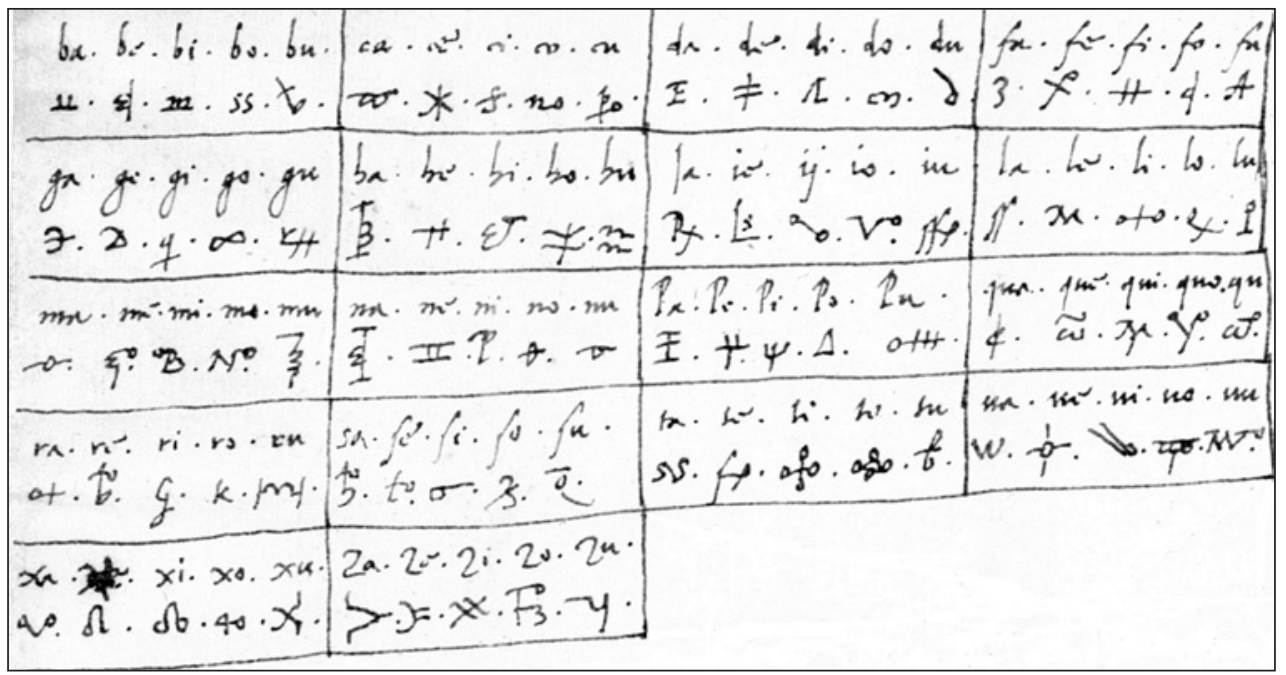

Lo mismo sucede en los cuatro bloques siguientes de sílabas con tres letras (trigramas) y un cuarto con cuatro (tetragrama):

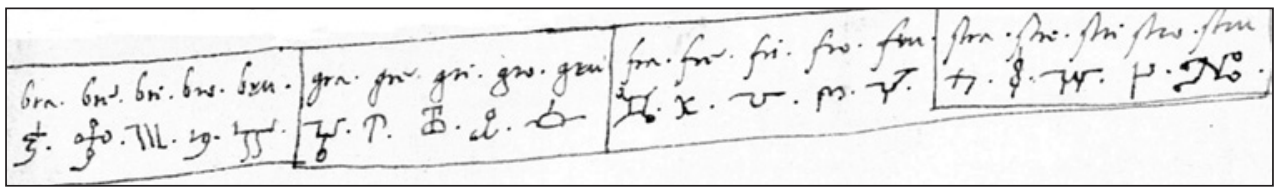

El resto de la clave está compuesta con una serie de palabras escogidas. Unas que hacen relación a diversos territorios vinculados con la defensa del reino de Navarra y a la política internacional aludidos anteriormente, como «Funterabía», «Pampaluna»o «Baiona»; a los principales protagonistas de la política del momento: «El papa» (León X, Adriano VI o Clemente VII), «Imperator» (Maximiliano I de Habsburgo o Carlos V), «Re de França» (Francisco I), «Re de Spagna» (Fernando el Católico o Carlos I) y el «Re de Engleterra» (Enrique VIII); a conceptos bélicos: «gente de guerra», «armata» (armada), «sniçari» (suizos); y a cuestiones presumiblemente económicas: «Ducados». Todas ellas cuentan con su correspondiente signo o ideograma.

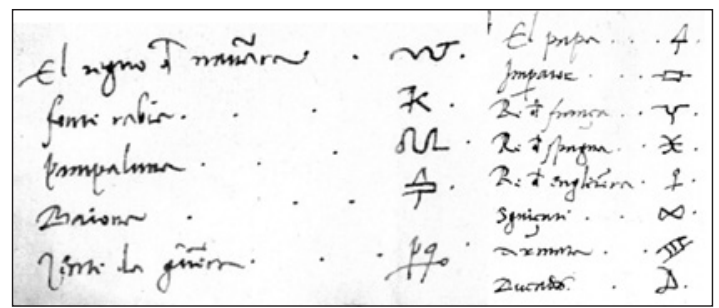




\section{La cifra para la correspondencia con Juan de Alarcón [1529]}

De origen castellano, Juan de Alarcón aparece por primera vez en Navarra vinculado a la figura de Juan Rena, su señor, en la década de 1520-1530. Se convierte entonces en uno de sus hombres de confianza. Rena le llama 'su criado' en el sentido de agente, como sucede con Juan Vallés. Vivió Alarcón en Pamplona en casa de Juan Rena, de él aprendió el manejo de las cuestiones contables en las que su señor era un experto. Cuando Juan Rena dejó el reino para ocuparse de asuntos de mayor calado en la corte, fue nombrado su apoderado el 12 de abril de 1529, para ejercer en nombre de Rena el cargo de pagador real de obras y gastos extraordinarios. A la muerte de Juan Rena en 1539 , fue nombrado pagador titular y en ese puesto siguió hasta su asesinato en $1551^{21}$. La utilización de la clave hay que enmarcarla durante la primera mitad de 1529. Se sabe que la cifra correspondió al propio Juan de Alarcón. Al verso de ésta aparece redactado: «Cartas y escripturas y otras cosas que se han de tornar a ver, quando plaziendo a Dios Alarcón vuelva desde Toledo, porque son suyas», y a un nivel inferior «d'Alarcón» ${ }^{22}$. Alarcón estuvo en Toledo entre el 16 y el 29 de abril ${ }^{23}$. Su actividad como pagador real está en consonancia con las palabras escogidas para confeccionar el vocabulario: personajes, edificaciones, instituciones..., como más adelante se comprobará. Esto queda reflejado en una carta del 21 de septiembre de 1529 de Alarcón a su mentor en la que trata de los bastimentos de trigo para la fortaleza de Pamplona y del estado de las rentas de la abadía de Usún, entre otros asuntos, y en otra, fechada el 15 de noviembre del mismo año, en la que vuelve a referirse sobre el arcedianato de Usún ${ }^{24}$.

Respecto al criptoanálisis de la clave o cifra, a cada letra que compone el alfabeto le corresponde dos signos (ideogramas) a utilizar de forma indistinta:

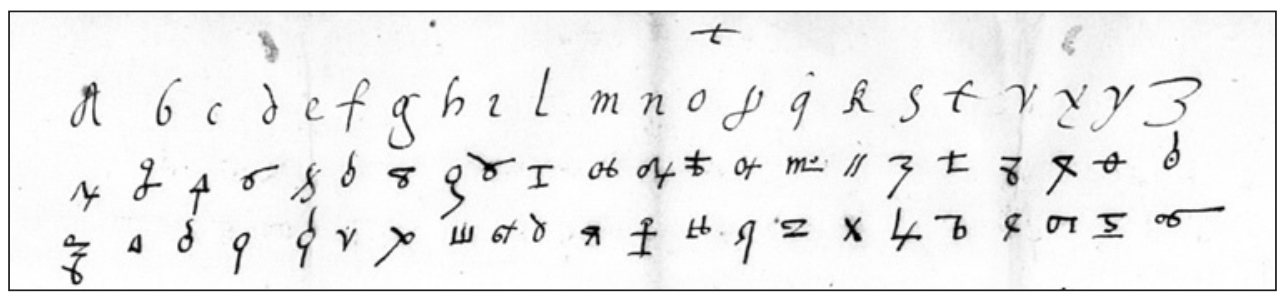

No existen símbolos que representen las letras dobles (rr, ss y 11), como en otras claves de la época ${ }^{25}$, pero sí signos carentes de significado, que se describen como «todos los caracteres como estos u otro quolesquier que tuviere puntos ençima son nullos». Es

${ }^{21}$ Mercedes Chocarro Huesa y Félix Segura Urra, Inventario de la documentación de Rena ..., pp. 32 y 70-74.

22 AGN, Archivos Particulares-Rena, caj. 86, $\mathrm{n}^{\circ}$ 5-21.

23 Mercedes Chocarro Huesa y Félix Segura Urra, Inventario de la documentación de Rena ..., p. 292.

24 AGN, Archivos Particulares-Rena, caj. 6, no 5-9 y AGN, Archivos Particulares-Rena, caj. 6, no 5-13.

25 Juan Carlos Galende Díaz, "La correspondencia cifrada...., p. 498. 
decir, cualquier signo que tuviese un punto en la parte superior no había que tenerlo en cosideración. Los ejemplos que se redactan son los siguientes:

$$
\dot{0}=\dot{H} \dot{\infty} \dot{8} \dot{8}
$$

Las representaciones de las palabras escogidas para elaborar el vocabulario cifrado («protonotario» ${ }^{26}$, «hazienda», «dineros», «Usún», «La yglesia de Panplona» ${ }^{27}$, «El visorey» ${ }^{28}$, «trigo», «fortaleza», «recabdo», «castillo», «obras» ${ }^{29}$, «Juan Rena»y «Alarcón»), son sustituciones literales, conformadas por trigramas. No extraña la inclusión en dicho vocabulario las alusiones explícitas a Juan Rena y a Juan de Alarcón. De hecho, ambos debían tener la misma clave para poder descifrar los mensajes que uno y otro se enviaban recíprocamente, confirmando el secretismo incluso de quien era el remitente y el receptor de las misivas. Un ejemplo del interés del veneciano por estar al corriente de los asuntos que le concernían especialmente durante sus ausencias del reino:

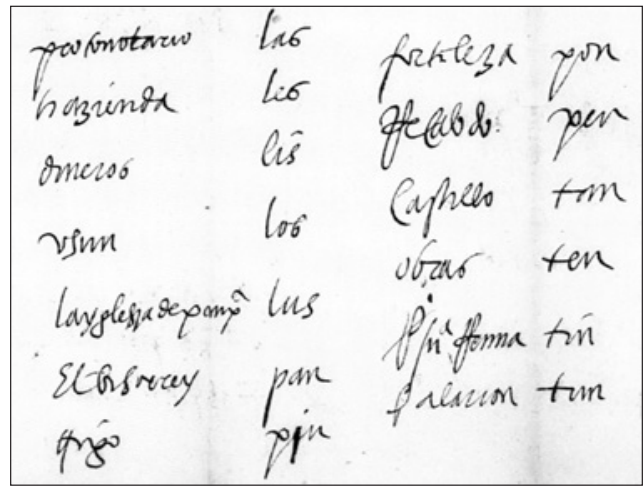

\footnotetext{
26 Desde finales de 1528 ejerce como protonotario de Navarra Martín de Echaide (Fernando SERRANO LARRÁYOZ, "Juan Vallés (c. 1496-1563)...", p. 29).

27 Juan Rena fue presentado por el monarca como arcediano de Usún en octubre de 1526, lo que le permitió ingresar en el cabildo, aunque no llegó a profesar como canónigo. Al poco tiempo lo permutó con Remiro de Goñi y obtuvo el cargo de tesorero de la catedral (agosto de 1530). Desde ese momento consiguió controlar las rentas del cabildo de la catedral de Pamplona (Mercedes Chocarro Huesa y Félix SEgura UrRA, Inventario de la documentación de Rena..., p. 119).

28 En mano del virrey estaba la capacidad de dar órdenes de pago (nóminas) al pagador para abonar los servicios militares prestados, los trabajos realizados o los materiales comprados o suministrados (Mercedes Chocarro Huesa y Félix Segura Urra, Inventario de la documentación de Rena..., pp. 301). El virrey que ejercía en 1529 era: Martín de Alonso Fernández de Córdoba y Velasco, conde de Alcaudete (Ángel J. MarTíN DuQue (dir.), Gran Atlas de Navarra. Historia, Caja de Ahorros de Navarra, Pamplona, vol. 2, 1986, p. 253). 29 Del periodo al que se atribuye la clave hay gran número de libranzas del virrey sobre repartimientos de peones, nóminas, cuentas y expedientes de adjudicación de obras referentes a la fortaleza y castillo de Pamplona.
} 
En el extremo inferior derecho de la clave hay un texto cifrado que dice lo siguiente: «Aher ${ }^{30}$ me mandó el visorey que diese di». Probablemente una prueba sin más pretensiones, porque la frase no está completa ni tiene sentido alguno en su contexto. No obstante es interesante acreditar su utilización:

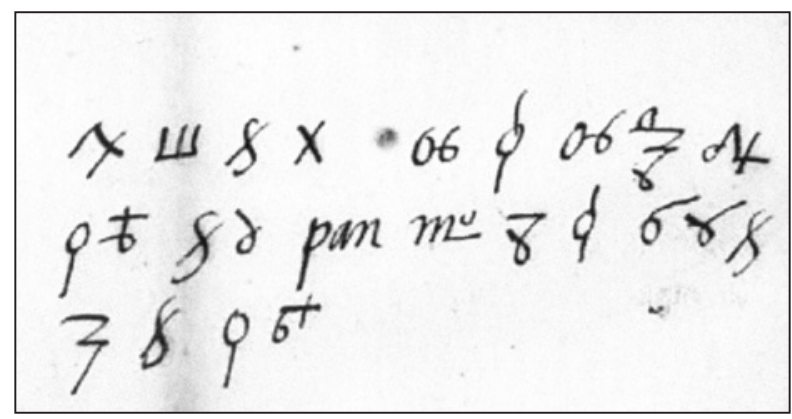

\section{Consideraciones finales}

El uso de claves y correspondencia de carácter secreto en el archivo personal de Juan Rena, está en consonancia con los planteamientos históricos que consideran al reinado de los reyes Católicos como el inicio del desarrollo de la criptografía en la España del Renacimiento. Las características de las claves o cifras incluidas en este trabajo siguen los parámetros generales de las que otros investigadores han estudiado para esta misma época. Resultan ejemplos prácticos de la importancia que tenía la escritura, en este caso la escritura cifrada, en las relaciones de poder. Las claves aquí mostradas están relacionadas con la correspondencia de un personaje de alto rango en la Administración del reino de Navarra durante el reinado de Fernando II de Aragón (el Católico) y Carlos I de España y V de Alemania. Textos vinculados a su persona utilizados no solo para cumplir los deseos de sus soberanos sino también de sus propias aspiraciones de promoción en los ámbitos cortesano y eclesiástico.

Por lo que respecta a las claves, comprobamos el uso generalizado de diversos alfabetos, aunque con ciertas singularidades en unos y otros. Así el alfabeto de 1521-1524 utiliza letras de manera aleatoria junto con unos pocos signos, mientras que el de 1520 mezcla signos y números. Algo más complicado es el alfabeto que utilizaron Juan Rena y Juan de Alarcón en 1529, al que le corresponden dos signos por letra.

El nomenclátor de 1521-1524 lo componen veintidós bloques de sílabas (bigramas, trigramas y tetragramas), cada una de ellas con su correspondiente signo, probablemente

\footnotetext{
30 Puede comprobarse un error en la disposición de los signos criptográficos, habiéndose colocado uno de los que representan a la «h» en vez de los de la «i». Si se hubieran dispuesto los signos de esta última manera resultaría la palabra «Aier», más acorde con el sentido del texto.
} 
uno de los ejemplos más antiguos conservados en España de este tipo de codificación ${ }^{31}$. Más frecuente era el empleo de signos en las palabras escogidas para utilizar con asiduidad en el contenido de los mensajes, como sucede en la aludida clave de 1521-1524. Por su parte, la de 1529 no utiliza signos sino que se basa en sustituciones literales conformadas por trigramas. Esta última es la única clave en utilizar signos nulos y en explicar cómo se podían añadir otros sin valor. No se da la circunstancia, sin embargo, como sucede en otros casos de la época e incluso en alguna de las claves navarras conocidas del periodo bajomedieval, de sustituir los diferentes personajes públicos o lugares geográficos mediante palabras de sentido oculto. Tampoco hay constancia en ninguna de las claves estudiadas de signos que representen letras dobles. En definitiva, haciendo referencia a los métodos utilizados en las tres claves, se puede afirmar que fueron los más habituales de la época, probablemente los más seguros para la transmisión de información oculta.

Fecha de recepción: 5 de abril de 2014

Fecha de aceptación: 6 de mayo de 2014

31 Una forma semejante de codificar puede comprobarse entre las cifras de Lope de Soria, consejero, embajador español en Génova y Venecia, con Carlos V, con el rey de Hungría Fernando, con Antonio de Leiva y con el conde de Borrello (Juan Carlos Galende Díaz, "La correspondencia cifrada...,", p. 517). 